\title{
DEBATES
}

\section{Dilemas da Grande Estratégia das Forças Armadas do Brasil nos anos 1980 e 1990: o debate interno em um sistema internacional em transição}

\author{
Brazil's Armed Forces Grand Strategy dilemmas in the 1980s and \\ 1990s: the internal debate in face of an international system in \\ transition
}

\section{Raul Cavedon Nunes \\ Eduardo Munhoz Svartman}

\section{Resumo}

Este trabalho tem como objetivo descrever os principais dilemas da Grande Estratégia das Forças Armadas Brasileiras nos anos 1980 e 1990. Nos anos 1980, a Guerra das Malvinas e o reordenamento da política externa brasileira, somados ao contexto de redemocratização, ensejaram revisóes da Estratégia e das Doutrinas Militares oriundas do período da Guerra Fria. Nos anos 1990, o novo contexto internacional ampliou o dilema sobre a finalidade das Forças Armadas, com opinióes variando entre a dissuasão, o combate a ilícitos internacionais, a proteção ao meio ambiente e a atuação em Operaçóes de Paz da ONU. O debate interno foi analisado a partir de artigos publicados por oficiais nas revistas profissionais "A Defesa Nacional" e "Revista da ESG". Argumenta-se que os consensos e dissensos desta produção ideacional podem ser observados na Política de Defesa Nacional, de 1996.

\section{Palavras-chave}

Brasil; Grande Estratégia; Forças Armadas; Institucionalismo Discursivo.

\section{Abstract}

This paper aims to describe the main dilemmas of the Brazilian Armed Forces Grand Strategy in the 1980s and 1990s. In the 1980s, the Malvinas/Falklands War, the reordering of Brazilian foreign policy and the redemocratization process led to a review on the Cold War's Strategy and Military Doctrine. In the 1990s, the new international context strengthened a debate over the Armed Forces purposes, with opinions varying between deterrence, fighting international illicit acts, protecting the environment and acting in UN Peacekeeping Operations. The internal discussion was analyzed based on the articles published by militaries in professional journals like "A Defesa Nacional" and "Revista da ESG". This work argues that the consensus and dissent present in the ideational production can be observed in the Brazilian National Defense Policy of 1996.

\section{Keywords}

Brazil; Grand Strategy; Armed Forces; Discursive Institutionalism. 


\section{Introdução ${ }^{1}$}

As décadas de 1980 e 1990 constituíram uma fase de redefinição estratégica e doutrinária para as Forças Armadas brasileiras. Até o final dos anos 1970, a preparação militar do país, ainda que com contornos particulares em cada Força, era de caráter defensivo, buscando lidar com hipóteses de guerra ligadas ao contexto da Guerra Fria: (i) Guerra Revolucionária na América do Sul, (ii) Guerra Convencional ou Nuclear entre os blocos ocidental e o soviético, (iii) Guerra Geral com um inimigo interno agindo como agente do bloco soviético, e (iv) Guerra Convencional na América do Sul (MARQUES, 2001).

Nos anos 1980, a confluência de três fatores - a aproximação diplomática entre Brasil e Argentina, a redemocratização e o fim da Guerra Fria - levaria ao que Fucille (2006, p. 125) denominou "crise de identidade militar". A Guerra das Malvinas (1982), somada à alta das taxas de juros norte-americanas no ano anterior, fortaleceu a percepção de que o confronto "leste-oeste" estava dando espaço para a emergência de embates "norte-sul", com prejuízos para potências médias em ascensão, como o Brasil.

Entretanto, ao passo que a diplomacia brasileira já havia assumido uma orientação mais pragmática e orientada à busca por maiores margens de autonomia desde a década anterior (CERVO; BUENO, 2015), no meio militar as redefinições estratégicas se deram de forma mais lenta e desencontrada. A diversificação de fornecedores e a produção doméstica de sistemas de armas consolidaram-se como um dos eixos da Grande Estratégia (GE)² brasileira (SVARTMAN, 2011); contudo, particularmente no Exército, as agendas de contra-insurgência e de manutenção de

\footnotetext{
${ }^{1} \mathrm{O}$ presente trabalho foi realizado com apoio da Coordenação de Aperfeiçoamento de Pessoal de Nível Superior - Brasil (CAPES) - Código de Financiamento 001.

${ }^{2} \mathrm{O}$ conceito de Grande Estratégia aqui utilizado abarca tanto a Estratégia quanto a Doutrina Militar e sua relação com as demais esferas de planejamento do Estado, como a Diplomacia. Em termos sucintos, enquanto a Estratégia define os objetivos políticos do uso ou ameaça do uso da força, a Doutrina Militar estabelece os conceitos, normas e procedimentos que orientam o modo de fazer a guerra de uma determinada Força Armada (BRASIL, 2007; POSEN, 1987). Partindo do pressuposto de Clausewitz [1832] (1984) de que a guerra é a continuação da política por outros meios, depreendese que escolhas em termos operacionais são um reflexo dos objetivos estratégicos a serem alcançados. Não é objetivo deste artigo aprofundar o debate sobre o conceito de Grande Estratégia; contudo, cabe notar que a adoção do Institucionalismo Discursivo afasta-se das concepçóes centradas nos condicionantes sistêmicos. De forma distinta a autores como Posen (1987), este trabalho parte do pressuposto de que as políticas públicas são formuladas a partir da articulação política, burocrática e discursiva interna.
} 
prerrogativas políticas e corporativistas no processo de transição para a democracia ainda se faziam presentes (ZAVERUCHA, 1994; SOARES, 2006; D’ARAÚJO, 2010). Somente nos anos 1990 seria formado um relativo consenso de que a GE brasileira deveria adaptar-se ao que seria denominada "Nova Ordem Mundial" (VIDIGAL, 1991; MATTOS, 1992a e 1992b; COSTA, 1994; OLIVEIRA, 1994; MORAES, 1997; CASTRO, 1997).

Desta forma, cabem as seguintes perguntas: como os militares brasileiros perceberam as mudanças estratégicas internacionais e quais foram as soluçôes propostas? Visando responder a essas questóes, este artigo buscou identificar as principais linhas do debate das Forças Armadas acerca da GE a ser adotada pelo Brasil nas décadas de 1980 e 1990.

Em termos teóricos, adotou-se a perspectiva do Institucionalismo Discursivo, que pressupôe que as mudanças institucionais ocorrem a partir da articulação de Comunidades Epistêmicas e Espaços Discursivos capazes de gerar novas ideias e consensos políticos (Figura 1) (SCHMIDT, 2008; JENSEN, 2016). Em linha semelhante ao Institucionalismo Histórico-Sociológico, o Institucionalismo Discursivo adota uma definição das instituições "[...] simultaneamente como estruturas e construtos internos aos agentes, cujas 'habilidades ideacionais' e 'discursivas' advogam em prol de uma abordagem das instituiçôes mais centrada nos agentes" (SCHMIDT, 2008, p. 305). Entretanto, diferentemente da visão anterior, possui uma forte ligação com as teorias pós-estruturalistas, ou seja, que visam investigar o poder das ideias, do discurso e dos textos. Em suma, visa aplicar o que Der Derian e Shapiro (1989, p. 6) denominaram "abordagem intertextual”.

Segundo Zimmerman (2016), o Institucionalismo Discursivo tem como objetivo investigar a criação de "espaços discursivos" e sua influência nos processos políticos e nas instituiçốes. As comunidades epistêmicas, por sua vez, são formadas por meio da coordenação de discursos, seja ela ao nível internacional ou ao nível nacional. Neste sentido, os atores são capazes de produzir "espaços discursivos", ou seja, meios de propagação de um discurso ou de um determinado conjunto de ideias que visam influenciar um determinado processo político ou instituição. 
Figura 1 - Ciclo da influência ideacional

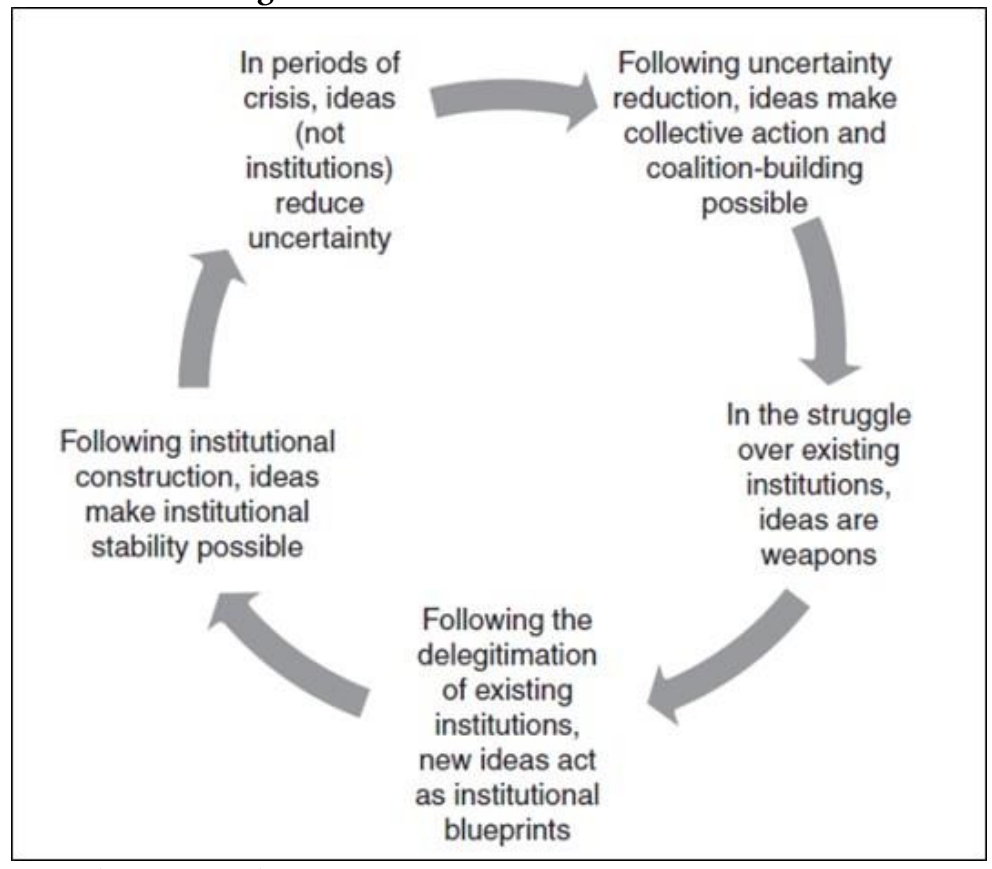

Fonte: Zimmerman (2016, p. 19).

A partir de uma crise, as ideias seriam responsáveis por organizar a ação coletiva e a construção de coalizões (espaço ideacional). Após, segue uma disputa política por espaço, cujas armas incluem a produção e a propagação de ideias. Com a deslegitimação das instituições existentes, o novo corpo de ideias passa a dar sustentação para novas instituiçóes ou para novas diretrizes.

"Choques externos", como mudanças no sistema internacional, afetam a estratégia dos países; contudo, a resposta a essas mudanças depende também da maneira com que essas mudanças são avaliadas pelos diferentes atores domésticos e, dentre as opçóes formuladas, quais passam a informar a nova estratégia. $\mathrm{O}$ desenvolvimento ou incorporação de novas concepçóes estratégicas é um processo complexo, que requer um trabalho longo não apenas de produção de ideias, mas também de circulação e promoção das mesmas, feito por grupos específicos (JENSEN, 2016). Em países com maior controle civil sobre os militares, esse processo envolve a formação de comunidades epistêmicas e grupos de interesse envolvendo o campo político, a burocracia civil e os militares; no caso brasileiro em 
questáo, o elevado grau de autonomia militar reduzia os atores quase que exclusivamente às forças armadas.

Em função disso, os dados coletados para este artigo são os artigos publicados por oficiais das Forças Armadas brasileiras em dois importantes periódicos profissionais: "A Defesa Nacional" e a "Revista da ESG". Ambas as revistas consistem em espaços de publicações de artigos de oficiais das três forças (com alguns autores civis), que permitem revelar as diferentes posições acerca da GE brasileira nessas décadas. Foram levantados um total de 49 artigos, sendo 13 da Revista "A Defesa Nacional" e 36 da "Revista da ESG", publicados nas décadas de 1980 e 1990. O critério de seleção dos artigos foi a abordagem de assuntos relacionados aos objetivos estratégicos brasileiros. Particular destaque foi dado aos artigos de militares que desempenharam funções de planejamento ou de execução de programas estratégicos em suas forças ou no governo federal, assim como para aqueles que desempenhavam funções intelectuais junto ao meio militar brasileiro da época.

O presente artigo está dividido em três seções, além desta introdução e da conclusão. A primeira seção discute o contexto internacional do final dos anos 1970 e início dos 1980, assim como a resposta diplomática brasileira e as diferentes visóes que circularam nos periódicos militares pesquisados. Na segunda seção é analisada a produção ideacional do imediato pós-Guerra Fria e, na terceira, apresenta-se a repercussão daquelas ideias no primeiro documento oficial ostensivo que apresentava a Grande Estratégia brasileira, a Política de Defesa Nacional (PDN), publicada em 1996.

\section{Anos 1980: Contexto internacional, reorientação estratégica regional e o debate interno}

No final dos anos 1970, os governos militares enfrentaram grandes desafios em sua política externa ${ }^{3}$, levando-os a adotar uma postura mais pragmática frente à Guerra Fria. Sennes (2003) denominou esta postura como princípio da diversificação de parcerias internacionais: (i) a aproximação com os países europeus (Alemanha, França e Inglaterra) e com o Japão, e (ii) o aumento das relaçóes econômicas e políticas com os países da América Latina, da África e do Oriente Médio,

\footnotetext{
${ }^{3}$ Com a eleição de Jimmy Carter nos Estados Unidos da América (1976), seriam intensificadas as pressões sobre o Brasil acerca do tema dos direitos humanos. Tal quadro, aliado à insatisfação brasileira quanto aos frutos do Acordo Militar Brasil-Estados Unidos de 1952, levou à denúncia deste tratado em 1977.
} 
principalmente das exportaçóes de produtos industrializados (SENNES, 2003). Segundo Vizentini (1998), os governos Geisel e Figueiredo representaram o "apogeu da multilateralização e da mundialização da política externa brasileira" (VIZENTINI, 1998, p. 362).

Por um lado, a Guerra Fria e o combate ao comunismo ainda estavam presentes no cálculo estratégico dos militares brasileiros. Exemplo disso foi a série "Conhecendo o Inimigo Interno", publicada pela revista "A Defesa Nacional" em 1978. O próprio conceito de "terrorismo" era atrelado às ações do bloco soviético (MELO, 1980). Segundo o Vice-Almirante José Maria do Amaral Oliveira (1982, p. 34), referindo-se à União Soviética, “[...] a posse do controle do Estado e a transformação do Brasil no grande centro comunista americano seria uma conquista de grande valor". No quadro da Guerra Fria, o poder naval soviético era visto como uma potencial ameaça no Atlântico Sul "[...] em face dos pontos de apoio que possui nos países do Terceiro Mundo, [...] o que lhe permite movimentação em todos os oceanos da Terra" (BAKKER, 1982, p. 30).

Por outro lado, era crescente entre as lideranças militares brasileiras a percepção de que era necessário ir além da disputa Leste-Oeste e do combate ao comunismo. Segundo o Tenente-Coronel de Infantaria João de Araujo Ribeiro Dantas (1978, p. 109): "As duas superpotências [...] não vêem com bons olhos a ascensão à potência por parte de qualquer Estado”. No âmbito regional, a partir de 1977 - mesmo ano do rompimento do Acordo Militar Brasil-Estados Unidos Brasil, Argentina e Paraguai iniciaram as negociações que culminariam no Acordo Trilateral Itaipú-Corpus em 1979. O Tratado seria seguido pelo Acordo de Cooperação para o Desenvolvimento e Aplicação dos Usos Pacíficos da Energia Nuclear, firmado em 17 de maio de 1980 por Brasil e Argentina (VIDIGAL, 2007).

O Tratado Interamericano de Assistência Recíproca (TIAR), até a Guerra das Malvinas (1982), ainda possuía certa credibilidade como aliança militar, como mostra o artigo do entáo Vice-Chefe do Estado-Maior das Forças Armadas, o Vice-Almirante Ibsen Gusmão Câmara (1980). Entretanto, a guerra entre Argentina e Grã-Bretanha fortaleceu a percepção de parte dos militares brasileiros acerca da fragilidade do TIAR como uma garantia de apoio militar dos EUA para os países da América do Sul frente a potências extrarregionais (CASTRO, 1983 e 1984). Segundo o contra-almirante Múcio Piragibe Ribeiro de Bakker:

[...] a chamada Guerra das Malvinas provocou uma crise dentro do próprio TIAR, em face do apoio dado pelos Estados Unidos à 
Inglaterra, uma potência extracontinental. As consequências desta crise, se não resultarem em completa dissolução do Tratado, irão requerer certamente total reformulação de seus conceitos e de seus dispositivos (BAKKER, 1982, p. 34).

A política externa do governo Figueiredo representou uma continuidade das diretrizes de seu antecessor, sendo Universalismo o conceito utilizado pelo então Ministro das Relações Exteriores, Ramiro Saraiva Guerreiro. A conjuntura, entretanto, era altamente desfavorável para o Brasil. A alta da taxa de juros nos EUA (1981) desencadeou o aumento da dívida externa dos países emergentes, que já sofriam os efeitos da Segunda Crise do Petróleo, de 1979. Halliday (1989) descreve os anos 1980 como a "Segunda Guerra Fria", na qual o bloco ocidental liderado pelos EUA acirrou a competição política, econômica e militar com a URSS, pressionando também algumas lideranças regionais do Terceiro Mundo. Além disso, o governo Reagan pressionava o Brasil para abandonar sua política de Reserva de Mercado da Informática, materializada na Política Nacional de Informática, de $1984^{4}$ (VIGEVANI, 1995).

Assim, nos anos 1980, houve um entendimento entre as Forças Armadas e o Itamaraty acerca do receio frente às pressóes dos EUA e da necessidade da manutenção do pragmatismo na política externa, o que levou à continuidade das iniciativas diplomáticas na América do Sul e no continente africano (BANDEIRA, 1989). Em 1981, os EUA propuseram a criação de um sistema de defesa coletiva que integrasse Brasil, Argentina e África do Sul - uma Organização do Tratado do Atlântico Sul (OTAS) - para contrarrestar uma possível intervenção cubana e soviética na América Central, Caribe e África Austral. Essa proposta foi declinada pelo Brasil, principalmente após a descrença no TIAR causada pela posição norteamericana na Guerra das Malvinas.

O tema da integraçáo sul-americana ressaltaria a importância da Amazônia como uma regiáo-chave para o planejamento estratégico brasileiro. Em 1985, o Conselho de Segurança Nacional elaborou a Exposição de Motivos no 018/1985,

\footnotetext{
${ }^{4}$ A origem desse programa pode ser encontrada em 1972, com a criação no governo Médici da Coordenação das Atividades de Processamento Eletrônico (CAPRE) e a criaçáo da empresa Computadores e Sistemas Brasileiros S.A. (COBRA), uma iniciativa da Marinha em conjunto com a USP e a firma inglesa Ferranti para desenvolver o protótipo do primeiro minicomputador brasileiro (BANDEIRA, 1989).
} 
dando origem ao Projeto Calha Norte ${ }^{5}$, que tinha como objetivo ampliar a presença do Estado na regiáo amazônica e revitalizar o Tratado de Cooperaçáo Amazônica (TCA) de 1978 (DINIZ, 1994). Ainda em 1982, em artigo na revista "A Defesa Nacional", o Coronel de Artilharia Agenor Francisco Homem de Carvalho destacou a importância estratégica da região tanto para o poder terrestre quanto para o poder naval (CARVALHO, 1982). Além disso, a ascensão de potências médias e regionais na América Latina levantavam questóes sobre o futuro das disputas no Atlântico Sul: "Não seria a crise das Malvinas (Falkland) apenas uma antecipação de problemas muito maiores, que provavelmente poderão vir a ocorrer, com relação a esses dois sistemas?” (BAKKER, 1982, p. 32).

A Antártida passou a ser elaborada como parte de uma grande região estratégica para o Brasil formada por Amazônia, Atlântico Sul, África e Antártida. Em artigo na revista "A Defesa Nacional”, o Capitão-de-Fragata Dino Willy Cozza (1982, p. 79) propôs-se a analisar o: "[...] Brasil face ao Oceano Atlântico, face à África na defesa do Atlântico, a importância da Antártida para o nosso país, mostrar a necessidade da formulação de uma linha de defesa avançada no Atlântico".

Além disso, o autor via no Tratado de Cooperação Amazônica (1978) e na construção da hidrelétrica de Itaipú "elementos de aglutinação" entre o Brasil e os demais países do continente, de forma sinérgica à estratégia marítima. Um dos pontos de apoio para a presença brasileira nesta grande região, para Meneses (1982), era a Ilha da Trindade, onde a Marinha mantém uma guarnição permanente.

Interessante notar que os militares brasileiros ligados ao Poder Terrestre compartilhavam essa percepção sobre a GE a ser adotada pelo país. Para o Coronel de Artilharia Octavio Tosta (1984, p. 121, grifo do autor): “[...] a Geopolítica do Brasil, na presente conjuntura, deverá limitar-se às seguintes linhas de ação política: Primeira - Integração com os países da América do Sul. [...] Segundo - Projeção sobre a África Ocidental. [...] Terceira - Presença na Antártida”.

O Coronel de Infantaria Gélio Augusto Barbosa Fregapani, analisando a conjuntura internacional, afirmou que "a situação mundial em meados da década de 1980 mostra a ruptura da bipolaridade" (FREGAPANI, 1985, p. 98). Assim, estabeleceu três opções estratégicas para o Brasil: "1 - Integrar-se no panamericanismo, [...] 2 - Integrar-se em um bloco latino-americano; 3 - Integrar-se em

\footnotetext{
${ }^{5}$ O Projeto Calha Norte foi desenvolvido em 1985 pelo Conselho de Segurança Nacional em parceria com diversos Ministérios para concentrar esforços militares e projetos econômicos e sociais na subregião situada ao norte da calha do rio Solimões/Amazonas, em especial junto à linha de fronteira.
} 
um bloco de língua portuguesa" (FREGAPANI, 1985, p. 95). Em relação à integração sul-americana, o Major João Roberto de Oliveira reconhecia a "falibilidade do sistema OEA-TIAR”, principalmente devido ao apoio dos Estados Unidos à GrãBretanha na questão das Malvinas, e que alertava para o fato de que "[...] a América do Sul não tem um organismo próprio com o objetivo de promover a integração dos países da área" (OLIVEIRA, 1987, p. 172). Assim, propôs a formação de "[...] um sistema próprio sul-americano, principalmente, no que se refere à defesa integrada da área” (OLIVEIRA, 1987, p. 173).

Em 1988, a Constituição Federal consagrou a integração regional como um dos objetivos centrais do Estado brasileiro: "A República Federativa do Brasil buscará a integração econômica, política, social e cultural dos povos da América Latina, visando à formação de uma comunidade latino-americana de naçôes" (BRASIL, 1988, Art. 4º , parágrafo único). O General de Exército Oswaldo Oliva ainda em 1988 semeou os parâmetros do que seria, nas décadas seguintes, denominado "entorno estratégico" brasileiro:

Por nossa posição geográfica, não há como esquecermos nossos vizinhos imediatos, os sul-americanos, e os próximos, os africanos da costa ocidental, em especial os de língua portuguesa [...]. Com os demais países da América do Sul, do Caribe e da América Central deveremos intensificar nossos laços políticos e econômicos (OLIVA, 1988, p. 11).

Em suma, nos anos 1980 pode-se observar um progressivo crescimento nos autores militares das opinióes favoráveis a uma postura mais autônoma do Brasil frente ao bloco ocidental na Guerra Fria, principalmente em direção à influência do país na América do Sul e no Atlântico Sul. Não havia, entretanto, um consenso quanto ao grau de relevância que ainda havia no conflito Leste-Oeste, assim como não estavam claros os objetivos principais da Grande Estratégia brasileira para os anos 1990. Essa transição será analisada na próxima seção.

\section{A transição para os anos 1990: A multipolaridade econômica e a Nova Ordem Mundial}

No final dos anos 1980, parte dos intelectuais militares brasileiros já percebia a emergência de um Sistema Internacional economicamente multipolar, apesar da primazia de Estados Unidos e União Soviética no campo político e militar. Segundo o General do Exército Oswaldo Muniz Oliva, Comandante e Diretor de Estudos da 
ESG: "Quer sob o aspecto da multipolarização econômica, quer sob o aspecto da bipolarização político-ideológica, avulta, cada vez mais, a importância do componente científico-tecnológico" (OLIVA, 1988, p. 10).

Segundo o Capitão-de-Mar-e-Guerra Sérgio Porto da Luz, havia uma "guerra surda de fundo econômico e científico-tecnológico" disfarçada em uma paz "imposta na área de influência dos Estados Unidos" (LUZ, 1989, p. 107). Na mesma linha de pensamento, Reis e Macedo Filho (1989) ${ }^{6}$ antecipavam o que analisaria Therezinha de Castro (1993) em uma visão geopolítica da mudança do eixo Leste-Oeste para o Norte-Sul. No âmbito do multilateralismo econômico, percebia-se um cenário desfavorável para os países do Terceiro Mundo:

As açóes de organismos como o FMI, o Banco Interamericano de Desenvolvimento, o Clube de Paris e o Banco Mundial pressionam as economias dos países do Terceiro Mundo para que se ajustem a determinados padróes de comportamento, sob pena de se verem colhidas em 'apartheids' econômicos, científicos e tecnológicos (FORTUNA, 1993, p. 11, grifos nossos).

Em 1991, a eclosão da Guerra do Iraque demonstrou que o fim da bipolaridade não significou o começo de uma "era de paz". Para Vidigal (1991, p. 25), com o fim da Guerra Fria, "[...] as estruturas de poder que garantiram a estabilidade do mundo por todo esse período também desapareceram”. A partir da visita ao Brasil, em fevereiro de 1992, do Secretário de Defesa dos Estados Unidos, Richard Cheney, o General-de-Divisão Carlos de Meira Mattos escreveu um artigo analisando as duas linhas de política externa em disputa nos EUA: uma que defendia o exercício de sua hegemonia internacional, e outra que argumentava em favor da cooperação com o grupo dos "grandes" por meio da ONU e dos organismos financeiros internacionais (Banco Mundial, FMI, Clube de Paris, etc.) (MATTOS, 1992a). Para o autor, a multipolaridade, ainda que desequilibrada, constituiria um cenário menos pior para o Brasil, que ainda poderia manter certo "peso estratégico" e atuar a partir do não-alinhamento automático ao bloco americano (MATTOS, 1992a).

Neste sentido, o fim da Guerra Fria também alterou a agenda diplomática dominante nas relaçóes internacionais. Contudo, os autores militares consultados

${ }^{6}$ CMG (FN) RRm Paulo de Oliveira Reis e CMG RRm José Macedo Filho, Chefe e Adjunto da Divisão de Assuntos Internacionais da ESG, respectivamente. 
nesta pesquisa viam com cautela a ascensão dos novos temas, alicerçados nos fóruns da ONU. No âmbito das relaçóes Norte-Sul, tais agendas poderiam trazer "consequências perversas nos campos político, econômico e social para o conjunto mais fraco" (REIS e MACEDO FILHO, 1989, p. 53). Se, por um lado, identificavase um "degelo" no sentido da paz, por outro, estavam: "[...] sendo valorizados temas profundamente sensíveis para países como o Brasil como, por exemplo, meio ambiente, propriedade intelectual, transferência de tecnologia, entre outros" (REIS e MACEDO FILHO, 1989, p. 50).

O tema do meio ambiente, por exemplo, era percebido como delicado para o Brasil devido às pressões pela internacionalização da Amazônia e as denúncias do desmatamento. Segundo Ibsen de Gusmão Câmara (1991, p. 73): "Outra falha grave é a utilização, infelizmente frequente, de temas ecológicos com objetivos políticos inconfessados. [...] Inúmeros exemplos poderiam ser citados em muitos países, inclusive no nosso". Segundo Gilberto Castro (1990), esse espaço deveria ser tratado como uma prioridade geopolítica. Em setembro de 1990, a Secretaria de Assuntos Estratégicos da Presidência da República (SAE) apresentou o projeto do Sistema de Vigilância da Amazônia (SIVAM), parte integrante do Sistema de Proteção da Amazônia (SIPAM) (LOURENÇÃO, 2003).

Os principais atores vistos com receio neste âmbito são as Organizações NãoGovernamentais (ONGs) tanto brasileiras quanto do exterior. De forma direta, o Capitão-de-Mar-e-Guerra Sérgio Porto da Luz cita diversos atores que estariam envolvidos no projeto de internacionalização da Amazônia, violando a soberania brasileira e dos demais países da região. Segundo Reis e Azevedo (1991), os pressupostos da "soberania relativa" e da "teoria dos enclaves" eram utilizados para legitimar açôes externas contra a soberania dos Estados da região. Para Luz (1990), observava-se a existência de: "[...] projetos internacionalizantes, seja através de certas pesquisas institucionais, seja através da ação de algumas Organizações NãoGovernamentais (ONG), de setores da Igreja, de empresas multinacionais e de ecologistas e ambientalistas manipulados" (LUZ, 1990, p. 164).

Segundo Cyrino (1994), a Conferência do Rio de Janeiro (ECO-92) foi essencial para o Brasil conceder nova roupagem ao debate do meio ambiente, levando em consideração os interesses dos países em desenvolvimento: "A tese da preservação pura e simples [...] contrapôs-se a consciência da preservação do homem regional através do 'desenvolvimento sustentado'" (CYRINO, 1994, p. 46-47). 
Em 1994, o termo "globalização" foi utilizado pela primeira vez na Revista da Escola Superior de Guerra. Segundo o Contra-Almirante e Assistente da Marinha na ESG, Luiz Sérgio Silveira Costa (1994, p. 41), “[...] nos anos 90, a globalização será o jogo dominante e o poder econômico tende a ser mais importante que o poder militar na caracterização da influência de uma nação". Em 1996, o então Ministro de Estado Chefe do Estado-Maior das Forças Armadas, General-de-Exército Benedito Onofre Bezerra Leonel, identificou a chegada da "Era da Informação", a partir da qual, segundo ele, haveria a necessidade de reavaliar os princípios da guerra gestados na Era Napoleônica e na Era Industrial. Isto porque havia muitas incertezas quanto às demandas para a preparação militar originadas na "[...] combinação das causas ou razóes da guerra tradicional, com a incidência de conflitos internos violentos" (LEONEL, 1996, p. 11). Em artigo no ano seguinte, indicou que a agenda das "novas ameaças" trazia consigo cenários estratégicos de conformação difusa, rápida e continuada evolução da doutrina, a permanente mutabilidade tecnológica e a descentralização das operações militares (LEONEL, 1997). Segundo Hernani Goulart Fortuna (1993, p. 9), “[...] os conflitos latentes e contidos pela dissuasão nuclear do mundo bipolar afloram em manifestações de caráter nacional, étnico, cultural, histórico e religioso".

Entretanto, tanto Leonel (1996 e 1997) quanto Mattos (1997) e Oliva (1996) identificavam os possíveis perigos oriundos da globalização, propagada por autores como Alvin Toffler (a Terceira Onda), Mc Luhan (Aldeia Global), Francis Fukuyama (O Fim da História) e John Naisbit (Megatrend 2000). Assim como debatido por Fortuna (1993), Vidigal (1996) temia que as elites brasileiras absorvessem a ideia de que, com o fim da Guerra Fria, as Forças Armadas brasileiras deveriam atender a missões tradicionalmente pertencentes às forças policiais.

De forma semelhante, o tema do desarmamento, gerenciado a partir dos tratados entre EUA e URSS, era visto por parte dos militares como perigoso para o Brasil. O debate já existente no Brasil acerca da aplicabilidade das Forças Armadas em operações internas de Garantia de Lei e Ordem (GLO) era reforçado por pressóes externas que propunham a especialização das capacidades militares dos países do Terceiro Mundo em missões semelhantes àquelas cumpridas pela polícia. Tal agenda estava atrelada ao pressuposto de que a segurança externa desses países seria garantida pelos Organismos Internacionais: "As questôes de segurança externa ficariam sob a esfera da competência dos Organismos Internacionais, que elegeriam tropas multinacionais, sob liderança e tutela dos países desenvolvidos, quando sempre 
prevalecem os interesses destes últimos no âmago das decisões" (FORTUNA, 1993, p. 13).

Deste modo, pode-se identificar nos anos 1990 o acréscimo de novos desafios aos formuladores da GE Brasileira: o fim da Guerra Fria e a ascensão de novos temas na agenda diplomática internacional, como o meio ambiente e os acordos de desarmamento. A resposta dos autores militares pode ser resumida em três pontos: um certo ceticismo frente aos possíveis benefícios do fim da Guerra Fria, a preocupação com a defesa da Amazônia, e o reconhecimento da necessidade de adaptação das Forças Armadas brasileiras aos novos padrôes tecnológicos em vigor. Como será discutido na próxima seção, tais desafios somaram-se aos já existentes na década de 1980, como a integração regional, a projeção no Atlântico Sul e a diversificação de parcerias estratégicas.

\section{As divergências sobre a Grande Estratégia Brasileira e a tentativa de sintese da Politica de Defesa Nacional (1996)}

Apesar de haver um relativo consenso acerca das mudanças no Sistema Internacional na passagem dos anos 1980 para a década de 1990, o mesmo náo pode ser dito acerca do rumo a ser tomado pelo Brasil em sua Grande Estratégia. Em relação à preparação militar, houve três grandes perspectivas. Primeiramente, alguns autores sustentaram a necessidade de construir capacidades convencionais para uma defesa estratégica regional, principalmente da Amazônia. Em segundo lugar, havia aqueles que defendiam a projeção de poder no Atlântico Sul em direção à África e à Antártida, em articulação com América Central e Europa. Por fim, existia uma posição que buscava conciliar os dois objetivos estratégicos, atentando para as mudanças no perfil das Forças Armadas brasileiras (Doutrina Militar) no sentido de obter maior mobilidade tática e estratégica. As diretrizes presentes na Política de Defesa Nacional (PDN) refletem uma tentativa de síntese dessas visóes, que são descritas nesta seção.

Em relação à primeira posição, Mattos (1991) afirma que o objetivo do Brasil é evitar um confronto Norte-Sul e garantir os interesses no âmbito da Convenção das Naçôes Unidas sobre o Direito do Mar. Para o autor, o país deve basear sua preparação militar no conceito de "Dissuasão Estratégica", que significa "[...] evitar o choque, a ruptura, impondo uma ameaça cujo preço o adversário saiba, a priori, que terá que pagar" (MATTOS, 1993, p. 85). Meira Mattos justifica essa abordagem pelo 
184 | Raul Cavedon Nunes e Eduardo Munhoz Svartman

fato de que seria improvável um confronto com os vizinhos continentais, diferentemente da possibilidade de agressóes externas à América do Sul.

Leonel (1996) possui uma perspectiva semelhante, afirmando, sobre as Forças Armadas brasileiras, que "[...] é indispensável que elas possuam um poder de dissuasão tal que desestimule qualquer tipo de 'aventura' contra a nossa soberania" (LEONEL, 1996, p. 25). Ainda que reconhecendo a agenda das novas ameaças, o então Ministro do Estado-Maior das Forças Armadas reafirmou o papel de dissuasão e defesa externa, inclusive em relação à participação do país em órgãos como a Organização dos Estados Americanos (OEA).

Diferentemente dos autores citados, Leite (1991) aproxima-se das outras duas visões, associando a ideia de Poder Marítimo à projeção de Poder Nacional, ou seja, à "[...] projeção sobre o espaço marítimo e as massas continentais periféricas" (LEITE, 1991, p. 137). Além disso, cita como hipóteses de guerra: (1) guerra na América do Sul, (2) guerra geral, (3) guerra defensiva, e (4) guerra na África ou Oriente Médio para proteger patrimônio brasileiro no exterior (LEITE, 1991).

Em linha de pensamento semelhante, Fortuna (1992), inspirado nas ideias de Alfred Mahan, preconiza: “[...] a manutenção de uma força naval com características que permitam flexibilidade no seu emprego e que atenda, satisfatoriamente, às necessidades de conflitos regionais ou à participação efetiva, em alianças, nos conflitos extrarregionais" (FORTUNA, 1992, p. 22).

Fortuna repetirá esta proposta em artigo de 1993, também na Revista da ESG: "Uma capacidade mínima de dissuasão, para fazer face aos possíveis conflitos de interesses regionais ou extracontinentais, onde um país como o Brasil possa estar envolvido" (FORTUNA, 1993, p. 13, grifos nossos).

A terceira linha de pensamento, ainda que passível de ser observada nos anos 1980, ganhou força a partir do fim da Guerra Fria, particularmente devido às novas agendas securitárias que se destacaram, como veremos nas próximas subseçóes.

\section{Novas Ameaças, Operações de Paz e a discussão sobre o papel das Forças Armadas}

O fim da Guerra Fria reacendeu um debate gestado ainda em meados da década de 1980: a finalidade das Forças Armadas brasileiras no contexto da redemocratização. As opinióes, neste caso, também variaram: por um lado, havia o argumento de que, diferentemente das forças policiais, a preparação militar do país deveria estar voltada para ameaças externas, sendo elas tradicionais ou não. Por outro, como é o caso de Figueiredo Filho (1985), então Comandante da ESG, o conceito de 
Segurança concedia às Forças Armadas um papel intrínseco de garantidor da ordem interna, além de proteger o país de ameaças externas (defesa nacional).

Vidigal (1992) posicionava-se contra a especialização das Forças Armadas para o combate a ameaças internas como o narcotráfico e a proteção do meio ambiente, afirmando que isso significaria "submeter-se, como sempre ocorreu no passado, aos interesses estratégicos da potência hegemônica" (VIDIGAL, 1992, p. 126). Para o autor, a América Latina deveria “[...] promover com sucesso a integração econômica e aprimorar a cooperação nas áreas política e militar", o que “[...] implica a manutenção de forças armadas suficientes para dissuadirem os países mais poderosos de impor a sua vontade" (VIDIGAL, 1993, p. 73).

Sérgio Porto da Luz (1989), por outro lado, expôs o debate acerca das chamadas "açôes complementares" das Forças Armadas, previstas pela Constituição de 1988, que envolvem o apoio à indústria e à infraestrutura, assim como o envolvimento em ações sociais e ocupação de territórios como a Antártica. Após ressaltar que a principal função das Forças Armadas é a defesa externa, coloca-se ao lado daqueles que apoiam essas açóes, argumentando que é um meio tanto para a constante preparação das Forças quanto para a captação de recursos: “[...] ao desempenhar funções e executar tarefas e funçôes complementares, a Força passa a ter argumentos e posiçóes políticas para, mais facilmente, obter recursos e realizar seu próprio desenvolvimento, do seu material, do seu adestramento e aprestamento" (LUZ, 1989, p. 112, grifos nossos).

Se nos anos 1980 predominava o debate sobre a segurança interna e as ações complementares, nos anos 1990 houve a ascensão da agenda das "novas ameaças", as consequências doutrinárias da Guerra do Golfo, e o aumento das Operaçôes de Paz no âmbito da Organização das Naçôes Unidas (ONU).

Autores como Faria (1991) e Costa (1994) argumentavam que as Forças Armadas do país deveriam enfatizar a profissionalização e a prontidão operativa, o desempenho tecnológico e a mobilidade como princípios de sua modernizaçáo. Tal percepção encaixa-se na terceira visão citada no tópico anterior, que enfatiza a necessidade de mudanças na estrutura e na Doutrina Militar das Forças Armadas brasileiras. Essa visão encontrava apoio no fato de que a participação em Operações de Paz por parte do Brasil exigiria maior capacidade de mobilidade estratégica e prontidão operativa. Moraes (1997), por exemplo, advogou em prol da ampliaçáo do escopo das operações de paz, reconhecendo que o Brasil "[...] pretende postular um lugar permanente no Conselho de Segurança, firmando sua posiçáo de liderança no 
contexto dos países da América Latina” (MORAES, 1997, p. 89). Para o autor, as Forças Armadas brasileiras devem envolver-se em "[...] operaçóes de paz que se utilizam do fator coerção [...] permitindo, assim, que essas adquiram experiência e possam efetivamente contribuir para o preparo e fortalecimento dos poderes Militar e Naval brasileiros" (MORAES, 1997, p. 90).

Meira Mattos (1992a), contudo, ao analisar a nova ordem internacional, via com cautela a questáo da participaçáo do Brasil nas operaçóes de paz da ONU. Em visão semelhante, Reis (1993) afirmava que a ONU poderia vir a "[...] tornar-se um instrumento de nova postura neocolonialista que vêm assumindo naçóes desenvolvidas" (REIS, 1993, p. 97). Sergio Domingues de Figueiredo, então Adjunto da Divisão de Assuntos Internacionais da ESG, reconhecia a frequente participação brasileira em missóes de paz por solicitação da ONU ou da OEA durante o século $\mathrm{XX}$; alegava, entretanto, que "[...] o Brasil é um país que jamais usou seu poderio militar em missóes que não fossem em defesa de seu território, hoje acrescido do mar patrimonial" (FIGUEIREDO, 1993, p. 88). Neste sentido, buscando conciliar as duas posições, para Luiz Filho (1995), o Brasil não deveria ultrapassar o limite das missões de manutenção da paz, violando a autodeterminação dos povos e a solução pacífica de controvérsias, princípios da Carta Magna do país.

\section{Os Reflexos na Politica de Defesa Nacional (1996)}

Em 1996, já no governo de Fernando Henrique Cardoso, houve a publicação da Política de Defesa Nacional (PDN), um documento destinado a expor os objetivos estratégicos da preparação militar brasileira. Elaborada pela Câmara de Relações Exteriores e Defesa Nacional (CREDEN) no âmbito do Conselho de Governo, a PDN sintetiza os consensos e discordâncias do debate presente nos autores analisados. Apesar de sua pequena extensão e rápida produção, como apontado por Alsina Júnior (2003) e Fuccille (2006), é propriamente nessas características que reside a importância de um escopo de ideias (Espaço Discursivo e Comunidades Epistêmicas) prontas para serem aplicadas na Estratégia e na Doutrina de um país.

Em relação ao Sistema Internacional pós-Guerra Fria, observa-se o mesmo consenso presente nos autores analisados sobre a multipolaridade econômica:

Com o fim da confrontação Leste-Oeste, verifica-se, no atual processo de reacomodação de forças, o surgimento de um ambiente internacional multipolar indefinido e instável, gerado pela falta de correspondência entre os centros de poder 
estratégico-militar, político e econômico, cuja evolução ainda é difícil de prever (BRASIL, 1996, p. 4, grifos nossos).

Além disso, o diagnóstico inicial inclui as "[...] novas regras [...] de convivência entre as naçôes", a "[...] participação crescente de atores nãogovernamentais”, a América do Sul com baixa probabilidade de conflitos internos, e a inclusão do Atlântico Sul como parte do espaço regional do país (BRASIL, 1996, p. 5). Em relação às novas ameaças, o documento assume a possibilidade de "[...] ação de bandos armados que atuam em países vizinhos, nos lindes da Amazônia brasileira, e o crime organizado internacional" (BRASIL, 1996, p. 6).

Já em relação aos objetivos estratégicos, é visível a tentativa de conciliar mais de uma perspectiva. O documento afirma que a PDN é "voltada para ameaças externas", destacando que o Brasil possui um perfil "ao mesmo tempo continental e marítimo", o que "[...] torna complexa a tarefa de planejamento geral de defesa" (BRASIL, 1996, p. 3). Em seus objetivos estratégicos, inclui a "contribuição para a manutenção da paz e da segurança internacionais", a "projeção do Brasil no concerto das nações" e a "manutenção dos interesses brasileiros no exterior" (BRASIL, 1996, p. 7). Entretanto, logo após, define uma "postura estratégica dissuasória de caráter defensivo", baseada na "rejeição à guerra de conquista" na "busca da solução pacífica de controvérsias” (BRASIL, 1996, p. 8).

A resposta para o dilema entre a postura estratégica defensiva e a possibilidade de operaçôes ofensivas encontra-se no próprio documento:

O caráter defensivo não implica que, em caso de conflito, as Forças Armadas tenham que se limitar estritamente à realização de operaçóes defensivas. [...] o País empregará todo o poderio militar necessário, com vistas à decisão do conflito no prazo mais curto possível e com o mínimo de danos à integridade e aos interesses nacionais (BRASIL, 1996, p. 8, grifos nossos).

Ainda assim, ao redigir as diretrizes para a execução da PDN, o documento inclui: a integração do Brasil aos regimes internacionais de desarmamento, incluindo armas nucleares, a participação em operações internacionais de manutenção da paz, o fortalecimento da integração regional, a manutenção da participação das Forças Armadas em ações complementares ou subsidiárias, a proteção da Amazônia e da faixa de fronteira, incluindo as áreas marítimas do Atlântico Sul (BRASIL, 1996). 
A tentativa de síntese encontrada pelo CREDEN para lidar com o problema da sustentabilidade da Política de Defesa de um país ao mesmo tempo continental e marítimo foi a necessidade de "[...] construção de um modelo de desenvolvimento que [...] compatibilize as prioridades nos campos político, social, econômico e militar, com as necessidades de defesa e de ação diplomática" e que também permita "o envolvimento dos segmentos acadêmico, científico-tecnológico e industrial do país" (BRASIL, 1996, p. 4, grifos nossos). Em suma, a busca de modernização tecnológica e escala produtiva daria condiçóes ao Estado brasileiro de atender todas as demandas estratégicas das Forças, ainda que muitas vezes de forma concorrente.

\section{Conclusão}

A partir do enquadramento teórico do Institucionalismo Discursivo, pode-se identificar no Brasil dos anos 1980 e 1990 a formação de Espaços Discursivos, desenvolvidos por militares e capazes de sintetizar as proposições existentes para a GE do país. Para Jensen (2016, p. 16), os militares podem ser caracterizados como um "tipo especial de comunidade epistêmica", pois possuem a capacidade de elaborar novos conceitos e teorias acerca das diretrizes de inserção internacional mais indicadas. Nesse sentido, as revistas militares como "A Defesa Nacional" e a "Revista da ESG" consistem em espaços de difusão do que o autor denomina como "Doutrina Informal", encontrada em artigos, discursos, ordens de serviço e memorandos (JENSEN, 2016).

No caso brasileiro, é interessante notar que as mudanças no Sistema Internacional e a transição política interna levaram à constante disputa entre antigas doutrinas militares, oriundas do contexto da Guerra Fria, e novas concepçôes sobre a finalidade das Forças Armadas do país para as próximas décadas. As principais alterações no contexto internacional e as linhas de pensamento dos militares brasileiros analisadas no artigo foram resumidas no Quadro 1 abaixo.

Quadro 1 - Contexto internacional e debate interno nos anos 1980 e 1990

\begin{tabular}{|c|c|c|}
\hline Década & Anos 1980 & Anos 1990 \\
\hline $\begin{array}{l}\text { Contexto } \\
\text { Internacional }\end{array}$ & $\begin{array}{l}\text { - Guerra das Malvinas (1982). } \\
\text { - Segunda Guerra Fria e pressóes } \\
\text { Norte-Sul. } \\
\text { - Busca de maior pragmatismo na } \\
\text { Política Externa Brasileira. }\end{array}$ & $\begin{array}{l}\text { - Fim da Guerra Fria. } \\
\text { - Guerra do Iraque (1991). } \\
\text { - Novas agendas securitárias. } \\
\text { - Globalização e "Era da Informação". }\end{array}$ \\
\hline
\end{tabular}




\begin{tabular}{|c|c|c|}
\hline $\begin{array}{l}\text { Pensamento } \\
\text { Militar Brasileiro }\end{array}$ & $\begin{array}{l}\text { - Desencontro de opiniōes frente à } \\
\text { Guerra Fria: alinhamento ou } \\
\text { autonomia? } \\
\text { - Priorização da Amazônia e do } \\
\text { entorno regional. } \\
\text { - Integração regional ganha força. } \\
\text { - Projeção para o Atlântico Sul e } \\
\text { para a Antártida. }\end{array}$ & $\begin{array}{l}\text { - Desconfiança quanto ao fim da Guerra } \\
\text { Fria como uma "Era de Paz". } \\
\text { - Receio frente aos novos temas como } \\
\text { meio ambiente e desarmamento. } \\
\text { - Divisão de opinióes quanto ao futuro } \\
\text { das Forças Armadas: entre a dissuasão } \\
\text { estratégica e a flexibilização estrutural para } \\
\text { o cumprimento de novas missóes. }\end{array}$ \\
\hline
\end{tabular}

Fonte: Elaboração própria.

A nova postura externa dos Estados Unidos (1976 em diante) e a Guerra das Malvinas (1982) fortaleceram a percepção de que o Sistema OEA-TIAR não garantiria a segurança dos países sul-americanos, levando parte dos militares brasileiros a apoiar a criação de um sistema próprio de segurança coletiva na região. De forma semelhante, a distensão da Guerra Fria levaria a mudanças na visão estratégica e doutrinária em direção a conceitos como dissuasão, proteção da Amazônia, combate a novas ameaças e a preparação para Operaçôes de Paz.

Assim, pode-se citar dois indicadores de mudanças institucionais que legitimaram o discurso presente nos artigos analisados. Primeiramente, o estabelecimento na Constituição de 1988 da integração latino-americana como um princípio das relações internacionais (parágrafo único do artigo $4^{\circ}$ ) teve ressonância na produçáo intelectual de diversos militares desde os anos 1980. O aumento das divergências brasileiras com a política externa norte-americana dos governos Carter e Reagan, assim como a Guerra das Malvinas, foram fatores importantes para esse processo.

Em segundo lugar, nos anos 1990, as diretrizes da Política de Defesa Nacional (1996) ilustram tanto o consenso acerca das mudanças políticas e econômicas do pósGuerra Fria quanto as divergências sobre a prioridade da GE brasileira a ser adotada para as próximas décadas. Embora existisse uma concordância sobre a multipolaridade econômica, as demandas estratégicas da preparação militar podem ser resumidas em quatro vertentes: (i) a prioridade da dissuasão convencional ou também denominada "dissuasão estratégica", (ii) a priorização do Atlântico Sul em direção à África e ao Caribe, (iii) a atenção às ameaças não-tradicionais como o narcotráfico, e (iv) a necessidade da preparação para Operaçôes de Manutenção da Paz da ONU. 
O CREDEN, nesse sentido, buscou formular uma síntese por meio da priorização do desenvolvimento econômico, industrial e tecnológico como forma a contentar todas as Forças, que possuíam grande autonomia na formulação de suas doutrinas e diretrizes de modernização militar. Mesmo com a presença constante do debate sobre a criação de um Ministério da Defesa (não abordado neste artigo), tal iniciativa seria executada somente em 1999, e sua efetividade ainda está em processo de estruturação.

Por fim, a abordagem teórica deste artigo, assim como o resultado da pesquisa, permite elaborar uma nova visão sobre o conceito de Grande Estratégia e o seu processo de formulação. Se, por um lado, Posen (1987) afirma que a Doutrina Militar e a GE são respostas do Estado a mudanças no Sistema Internacional, por outro, as visóes institucional e construtivista ressaltam o papel da articulação política e discursiva no processo de formulação das políticas públicas e do agendamento de pautas. Os Espaços Discursivos e Comunidades Epistêmicas são, portanto, essenciais para o estabelecimento de consensos e redes institucionais para o avanço de uma Grande Estratégia brasileira que responda às diferentes demandas do país tanto internamente quanto diante do Sistema Internacional.

- Raul Cavedon Nunes é Doutorando do Programa de PósGraduação em Ciência Política da UFRGS. E-mail: rcavedonnunes@gmail.com.

- Eduardo Munhoz Svartman é Doutor em Ciência Política pela Universidade Federal do Rio Grande do Sul. Professor do Programa de Pós-Graduação em Ciência Política da UFRGS. E-mail: eduardosvartman@gmail.com.

\section{Referências}

ALSINA JÚNIOR, João Paulo S. A síntese imperfeita: articulação entre política externa e política de defesa na era Cardoso. Revista Brasileira de Política Internacional, v. 46, n. 2, p. 53-86, 2003. Disponível em: <http://www.scielo.br/pdf/rbpi/v46n2/v46n2a03.pdf>. Acesso em: 01 abr. 2019.

BAKKER, Mucio P. Ribeiro de. Antártida: Uma nova perspectiva para o Brasil. A Defesa Nacional, n. $701,1982$. 
BANDEIRA, Moniz. Brasil - Estados Unidos. a Rivalidade Emergente (1950-1988). Rio de Janeiro: Civilização Brasileira, 1989.

BRASIL. Glossário das Forças Armadas. 4. ed. Ministério da Defesa, 2007. Disponível em: <https://www.defesa.gov.br/arquivos/File/legislacao/emcfa/publicacoes/md35_g_01_glossario_fa_4a ed2007.pdf>. Acesso em: 01 de abr. 2019.

Política de Defesa Nacional. Brasília, 1996. Disponível em: <http://www.biblioteca.presidencia.gov.br/publicacoes-oficiais/catalogo/fhc/politica-de-defesanacional-1996.pdfs. Acesso em: 01 abr. 2019.

Constituição da República Federativa do Brasil de 1988. Brasília, 1988. Disponível em: <http://www.planalto.gov.br/ccivil_03/Constituicao/Constituicao.htm\#art144>. Acesso em: 01 abr. 2019.

CÂMARA, Ibsen de G. Papel das Organizaçóes Não Governamentais no cenário ambiental brasileiro. Revista da Escola Superior de Guerra, n. 17, 1991.

. O pensamento estratégico brasileiro - projeção da nossa maritimidade na Estratégia Nacional.

A Defesa Nacional, n. 688, 1980.

CARVALHO, Agenor F. Homem de. A Bacia Amazônica: panorama atual e interesses marítimos. $A$ Defesa Nacional, n. 699, 1982.

CASTRO, Gilberto. Desenvolvimento da Amazônia brasileira: situação e perspectivas. Revista da Escola Superior de Guerra, n. 14, 1990.

CASTRO, Therezinha de. O Brasil e a Nova Ordem Mundial: enfoque geopolítico. Revista da Escola Superior de Guerra, n. 35, 1997.

. MERCOSUL: enfoque geopolítico. Revista da Escola Superior de Guerra, n. 26, 1993.

. O ser e o não ser do TIAR. A Defesa Nacional, n. 713, 1984.

- Relaçóes Brasil-Estados Unidos em face da dicotomia Norte-Sul e Leste-Oeste. A Defesa Nacional, n. 706, 1983.

CERVO, Amado Luiz; BUENO, Clodoaldo. História da Política Exterior do Brasil. Brasília: Editora da UnB, 2015.

CLAUSEWITZ, Carl von. Da guerra. Rio de Janeiro: Escola de Guerra Naval (ESG), 1984 [1832].

COSTA, Luiz Sérgio S. A complexa Nova Ordem Mundial. Revista da Escola Superior de Guerra, n. 29, 1994.

COZZA, Dino Willy da. A geoestratégia do Brasil. A Defesa Nacional, n. 701, 1982.

CYRINO, Roberto de O. O Atlântico Sul e os interesses brasileiros. Revista da Escola Superior de Guerra, n. 28, 1994.

DANTAS, João de Araujo R. Um estranho mundo novo. A Defesa Nacional, n. 675, 1978.

D’ARAÚJO, Maria Celina. Militares, democracia e desenvolvimento: Brasil e América do Sul. Rio de Janeiro: FGV, 2010.

DER DERIAN, James; SHAPIRO, Michael J. International/intertextual relations: postmodern readings of world politics. Toronto: Lexington Books, 1989.

DINIZ, Eugênio. Projeto Calha Norte: Antecedentes Políticos. 1994. 203 f. Dissertação (Mestrado em Ciência Política) - Faculdade de Filosofia, Letras e Ciências Humanas, Universidade de São Paulo (USP), São Paulo, 1994. Disponível em: <http://cpdoc.fgv.br/sites/default/files/militaresamazonia/txt_Eugenio_Diniz.pdf>. Acesso em: 29 maio 2019. 
FARIA, José da C. O Projeto de Reconstrução Nacional. Revista da Escola Superior de Guerra, n. 17, 1991.

FIGUEIREDO, Sergio D. de. A presença brasileira no cenário mundial contemporâneo. Revista da Escola Superior de Guerra, n. 24, 1993.

FIGUEIREDO FILHO, Euclydes de O. A Segurança Nacional e as Forças Armadas. Revista da Escola Superior de Guerra, n. 6, 1985.

FORTUNA, Hernani G. O desafio brasileiro nos anos 90. Revista da Escola Superior de Guerra, n. 24, 1993.

O poder marítimo como projeção do poder nacional. Revista da Escola Superior de Guerra, n. 23, 1992.

FREGAPANI, Gélio Augusto B. As guerras da Coreia, do Vietnã e das Malvinas e a proliferação nuclear. A Defesa Nacional, n. 720, 1985.

FUCILLE, Luís A. Democracia e questão militar: a criação do Ministério da Defesa. 2006. 291 f. Tese (Doutorado em Ciências Sociais) - Instituto de Filosofia e Ciências Humanas, Universidade Estadual de Campinas (UNICAMP), Campinas, 2006.

HALliDAY, Fred. La Segunda Guerra Fría. México: Fondo de Cultura Económica, 1989.

JENSEN, Benjamin M. Forging the sword: doctrinal change in the U.S. Army. California: Stanford Univesity Press, 2016.

LEITE, Guilherme de A. O Poder Marítimo e as projeções do Poder Nacional. Revista da Escola Superior de Guerra, n. 18, 1991.

LEONEL, Benedito O. B. As forças armadas brasileiras. Revista da Escola Superior de Guerra, n. 34, 1997.

Segurança e defesa no século XXI. Revista da Escola Superior de Guerra, n. 32, 1996.

LOURENÇÃO, Humberto José. A Defesa Nacional e a Amazônia: O Sistema De Vigilância Da Amazônia (Sivam). 2003. 233f. Dissertação (Mestrado Em Ciência Política) - Instituto de Filosofia e Ciências Humanas da Universidade Estadual de Campinas (UNICAMP), Campinas, 2003.

LUIZ FILHO, Arlindo. Força de Paz: A experiência brasileira. Revista da Escola Superior de Guerra, n. 31,1995 .

LUZ, Sérgio P. da. Compreensão da Amazônia: políticas e estratégias para integrá-la ao núcleo do Poder Nacional - inclui o desenvolvimento, a segurança e a defesa da Regiáo. Revista da Escola Superior de Guerra, n. 15, 1990.

. O Cidadão Militar na Atual Sociedade. Revista da Escola Superior de Guerra, n. 13, 1989.

MARQUES, Adriana A. Concepçóes de Defesa Nacional no Brasil: 1950-1996. 2001. 153 f. Dissertação (Mestrado em Ciência Política) - Programa de Pós-Graduação em Ciência Política, Universidade Estadual de Campinas (UNICAMP), Campinas, 2001.

MATTOS, Carlos de Meira. O Conflito da Globalização. Revista da Escola Superior de Guerra, n. 34, 1997.

. A Amazônia e a Dissuasão Estratégica. Revista da Escola Superior de Guerra, n. 26, 1993.

A missão das nossas Forças Armadas na perspectiva da Nova Ordem Internacional. Revista da Escola Superior de Guerra, n. 23, 1992a.

A Nova Ordem Mundial. Revista da Escola Superior de Guerra, n. 21, 1992 b.

. A importância geopolítica da Amazônia brasileira. Revista da Escola Superior de Guerra, n.

19, 1991. 
MELO, Francisco B. Torres de. Terrorismo. A Defesa Nacional, n. 692, 1980.

MENESES, Eurípedes Cardoso de. A Ilha da Trindade: Posto Avançado no Atlântico Sul. A Defesa Nacional, n. 701, 1982.

MORAES, Márcio B. A Guerra Civil na Ex-Iugoslávia. A participação do Brasil, sob a égide da ONU, na Força de Proteção da Ex-Iugoslávia. Revista da Escola Superior de Guerra, n. 34, 1997.

OLIVA, Oswaldo M. A Globalização. Revista da Escola Superior de Guerra, n. 32, 1996. 1988.

. ESG: Opçóes político-estratégicas para o Brasil. Revista da Escola Superior de Guerra, n. 9,

OLIVEIRA, João Roberto de. Áreas de fricção na América do Sul e seus reflexos na segurança e harmonia do subcontinente. A Defesa Nacional, n. 731, 1987.

OLIVEIRA, José Maria do A. A União das Repúblicas Socialistas Soviéticas. A Defesa Nacional, n. 699, 1982.

OLIVEIRA, Marcos. Nova Ordem, velhos problemas... Uma avaliação da conjuntura internacional. Revista da Escola Superior de Guerra, n. 29, 1994.

POSEN, Barry R. The sources of military doctrine: France, Britain, and Germany between the World Wars. New York: Cornell University Press, 1987.

REIS, Paulo de O. O Brasil no mundo de hoje. Revista da Escola Superior de Guerra, n. 24, 1993.

REIS, Paulo de O.; AZEVEDO, Pedro Ernesto M. de. Uma Especulação para o Ano 2003. Revista da Escola Superior de Guerra, n. 19, 1991.

REIS, Paulo de O.; MACEDO FILHO, José. O Brasil e o Mundo. Revista da Escola Superior de Guerra, n. 13, 1989.

SCHMIDT, Vivien A. Discursive Institutionalism: the explanatory power of ideas and discourse. Annual Review of Political Science, v. 11, p. 303-326, 2008. Disponível em: <https:/www.annualreviews.org/doi/abs/10.1146/annurev.polisci.11.060606.135342>. Acesso em: 01 abr. 2019.

SENNES, Ricardo Ubiraci. As mudanças da política externa brasileira na década de 1980: uma potência média recém-industrializada. Porto Alegre: Editora da UFRGS, 2003.

SOARES, Samuel Alves. Controles e autonomia: As Forças Armadas e o sistema político brasileiro (1974-1999). São Paulo: UNESP, 2006.

SVARTMAN, Eduardo Munhoz. Brazil-United States military relations during the Cold War: political dynamic and arms transfers. Brazilian Political Science Review, v. 5, p. 96-122, 2011. Disponível em: <http://oaji.net/articles/2014/645-1395683969.pdfs. Acesso em: 01 abr. 2019.

TOSTA, Octavio. Geopolítica do Brasil. A Defesa Nacional, n. 711, 1984.

VIDIGAL, Armando A. F. Estratégia e o Emprego Futuro da Força. Revista da Escola Superior de Guerra, n. 32, 1996. . Integração e Segurança. Revista da Escola Superior de Guerra, n. 24, 1993. . Integração e Segurança. Revista da Escola Superior de Guerra, n. 23, 1992.

. O Brasil e a Nova Ordem Mundial. Revista da Escola Superior de Guerra, n. 19, 1991.

VIDIGAL, Carlos Eduardo. Relaçóes Brasil-Argentina: a construção do entendimento (1962-1986). 2007. 339 f. Tese (Doutorado em Relaçóes Internacionais) - Programa de Pós-Graduação em Relações Internacionais, Universidade de Brasília (UnB), Brasília, DF, 2007. 
194 | Raul Cavedon Nunes e Eduardo Munhoz Svartman

VIGEVANI, Tullo. O Contencioso Brasil x Estados Unidos da Informática: uma análise sobre formulação da política exterior. São Paulo: Alfa-Omega, Editora da Universidade de São Paulo, 1995.

VIZENTINI, Paulo G. F. A Política Externa do Regime Militar Brasileiro: multilateralização, desenvolvimento e a construção de uma potência média (1964-1985). Porto Alegre: Ed. da Universidade/UFRGS, 1998.

ZAVERUCHA, Jorge. Relaçóes civil-militares no primeiro governo da transição brasileira: uma democracia tutelada. Revista Brasileira de Ciências Sociais, v. 9, n. 26, p. 162-178, out. 1994.

ZIMMERMAN, Erin. Think Tanks and Non-Traditional Security: Governance Entrepreneurs in Asia. New York: Palgrave Macmillan, 2016.

Texto recebido em 03 de janeiro de 2019. Aprovado em 20 de março de 2019. 